\title{
Modelling dishes and exploring culinary 'precisions': the two issues of molecular gastronomy
}

\author{
Hervé This* \\ INRA Group of Molecular Gastronomy, Laboratory for Chemistry of Molecular Interactions, Collège de France, 11 place Marcellin \\ Berthelot, 75005 Paris, France
}

\begin{abstract}
The scientific strategy of molecular gastronomy includes modelling 'culinary definitions' and experimental explorations of 'culinary precisions'. A formalism that describes complex dispersed systems leads to a physical classification of classical sauces, as well as to the invention of an infinite number of new dishes.
\end{abstract}

Soft matter: Colloids: Disperse system: Formalism: Food: Cooking

Science explores the world and looks for mechanisms of natural phenomena: geophysicists try to understand the surge of mountains, molecular biologists explore the genome, embryologists study the build-up of living organisms, astrophysicists are interested by the structure of the Universe, and chemists unravel the details of chemical processes... Every aspect of our environment is studied by a specific scientific discipline, using the experimental method, introduced by Galileo Galilei (introduced in practice only, as it was theoretically introduced before him by Francis Bacon; Largeault, 1988), and 'mathematics', because they are the language of the world (Galilei, 1623).

Cooking is such an important part of our world (even the smallest flat has a room for it) that it is worth specific scientific studies. The scientific discipline devoted to culinary transformations, and to gastronomical phenomena in general has been called Molecular Gastronomy by the late Nicholas Kurti and myself (This \& Kurti, 1994). Of course, this discipline is part of food science, but research is focused on (mainly home or restaurant) culinary transformations and eating phenomena rather than the physical and chemical structure of ingredients.

As recipes describe culinary transformations, it is useful to examine recipes, in order to understand the scientific strategy of the discipline. The following one is from a culinary book published in France at the beginning of the 20th century (Anonymous, 1905):

Take a dozen pears of middle size, remove the skin and put them immediately in cold water. Then melt $125 \mathrm{~g}$ of sugar with some water in a pan at low heat: as soon as the sugar is melted, add the pears, add some lemon juice if you want to keep the pears white; if you prefer them red, do not add lemon juice and cook them pan lined with tin.

In this recipe, the words in bold characters give a definition of the dish; it can be observed that this definition here is less than $10 \%$ of the recipe. The words in italics add 'precisions', a category that includes old wives' tales, proverbs, and sayings... Depending on the recipe and author, the precision content of recipes can vary considerably; for example, in some recipes from the French cook Jules Gouffé (1867), the precision percentage is nil. The pear recipe indicates the scientific strategy of molecular gastronomy: it should model the definitions and explore the precisions.

\section{We eat only disperse systems}

Modelling culinary transformations involves a comparison of food before and after cooking. In this regard, it is important to realize that dishes are disperse systems, i.e. what were formerly called colloids (Hiemnez, 1986; Hunter, 1986; Everett, 1988; Lyklema, 1991). Textbooks on disperse systems (De Gennes, 1997) generally begin by a presentation of simple disperse systems: gas, liquids or solids can be the disperse phase in a continuous phase that can be a gas, a liquid or a solid (Table 1).

For example, the name 'emulsion' was given in the 17th century by chemists to preparations that are white and thick as milk or cream (Bloch \& Von Wartburg, 1975); the word 'emulsion' comes from emulgere, which means 'to draw milk', and indeed milk is an emulsion. With foams, which are also disperse systems, emulsions have been thoroughly investigated by famous physicists such as Michael Faraday and Albert Einstein (Everett, 1988; Atkins, 1998; De Gennes et al. 2002). Other important disperse systems are gels that were first characterized in 1861 by Thomas Graham, who proposed a classification of different substances according to their 'diffusive power': the colloidal substances (from Greek kolla, glue) are slowly diffusing substances which are held in solution by 'feeble forces' (Djabourov, 1988). This particular case of gels is important as 'feeble forces' are related to soft matter (De Gennes, 1999) and supramolecular chemistry (Lehn, 1995). Among the colloidal materials, Graham grouped together hydrated silicic acid, hydrated alumina, starch, gelatin, albumen, etc. 
Table 1. The simplest disperse systems

\begin{tabular}{|c|c|c|c|}
\hline \multirow[b]{2}{*}{ Continuous phase } & \multicolumn{3}{|c|}{ Disperse phase } \\
\hline & Gas & Liquid & Solid \\
\hline Gas & Gas & $\begin{array}{l}\text { Liquid } \\
\text { aerosol }\end{array}$ & Solid aerosol \\
\hline Liquid & Foam & Emulsion & Suspension \\
\hline Solid & Solid foam & Gel & Solid suspension \\
\hline
\end{tabular}

Of course disperse systems more complex than emulsions, aerosols, gels, foams and suspensions, can be considered; physicists that study them focus generally on interfaces, so that only local descriptions of the systems are given (Dickinson, 1994). In a few cases, as in multiple emulsions, a name is given. However, in more complex - but familiar - systems, such as ice creams, the physical structure is rather complicated: gas (air) is dispersed (by 'foaming') in a condensed medium containing, in particular, ice crystals, proteins aggregates, sucrose crystals, fats (either crystals or liquid droplets), etc. (Sztehlo, 1994). What name should be given to such a physical system? 'Multiple suspension/foam/emulsion' is cumbersome and not very accurate, and 'ice cream' is probably not admissible in physics literature because it is restricted to food.

In order to describe the complex disperse systems present in the kitchen, we introduced (This, 2003) a new formalism based on the formalism introduced for chemistry by Antoine Laurent de Lavoisier (1792). This description is global, and not local; it is not restricted to food, but can lead to the invention of many new dishes.

\section{A simple formalism for physical transformations}

Let us be systematic and consider the following possibilities: the involved phases in food are gas, liquids or solids. The liquids, hydrophobic or hydrophilic, are named 'water' or 'oil', depending on their chemical composition. The solids are many, and they generally do not mix, so that different names should be given: solid 1, solid 2, etc. All these different phases can be dispersed, or mixed, or included into one another, or superposed...

Hence the proposal of using letters to envision rapidly all the possible systems. The phases can be written: $\mathrm{G}$ (for gas), $\mathrm{O}$ (for oil), W (for water), $S_{1}$ (for solid 1), $S_{2}$ (for solid 2), etc. The main processes can also be described by a few symbols: / (dispersed into), + (mixed with), $\supset$ (included into), $\sigma$ (superposed). In order to consider all possibilities, a number of $k$ phases $\mathrm{A}_{1}, \mathrm{~A}_{2}, \ldots$, $\mathrm{A}_{k}$ ( $k$ is a natural number) is chosen in the set $\left\{\mathrm{G}, \mathrm{O}, \mathrm{W}, \mathrm{S}_{1}, \mathrm{~S}_{2}\right.$, $\left.S_{3}, \ldots\right\}$. Then symbols from the set $\{l,+, \supset, \sigma\}$ are introduced between successive letters. And finally, parentheses are added.

Some other rules should be taken into consideration. For example, in order to get an unambiguous description of systems, the phases mixed $(\mathrm{A}+\mathrm{B}+\cdots)$ should be written by alphabetic order, as well as by order of growing complexity; e.g. S should come before $(\mathrm{E} / \mathrm{S})$. Then, when necessary, the proportions of the various phases can be given by a subscript, and the repetition of an operation can be marked as an exponent, with a symbol indicating the kind of process that is being repeated, and a number giving the number of repetitions.

For example, egg yolk is made of granules dispersed into a plasma, so that the $(\mathrm{S} / \mathrm{W})$ formula applies locally, but an echographic picture shows that the hen is producing yolk material of different compositions ('light yolk' and 'deep yolk') during the day and the night (Fig. 1), so that the global structure is composed of about eight layers of alternating composition: hence the formula $(\mathrm{S} / \mathrm{W})^{\supset 8}$.

Finally, more details could be added, such as the distribution of sizes of disperse structures, that can be indicated in brackets. In a mayonnaise made using a fork, for example, the diameter of oil droplets dispersed in the water phase (from the yolk and vinegar) is between 0.01 and $0.1 \mathrm{~mm}$ : the formula of the sauce can be written $\mathrm{O}\left[10^{-5}, 10^{-4}\right] / \mathrm{W}$. Finally, the level of description can be indicated, as shown using the case of aioli sauce, made from garlic ground with olive oil. A look at the microscopic structure of the sauce shows that it is made of oil droplets dispersed into water $(\mathrm{O} / \mathrm{W})$, but we know that there is a wealth of other structures smaller than the oil droplets, also dispersed in water: cell fragments, subcellular structures. One possibility is to indicate in brackets the smallest structures considered. In the case of aioli sauce, we would write:

$$
\mathrm{O}\left[10^{-5}, 10^{-4}\right] / \mathrm{W}\left[\mathrm{d}>6 \times 10^{-7}\right] \text {. }
$$

\section{How to use it?}

Is this global description of complex systems useful? The French chemist Antoine Laurent de Lavoisier (1743-1794) introduced the now classical formalism of chemistry because he wanted to make it easier to describe molecules and chemical processes:

In order to better show the state of affairs, and illustrate clearly in a single statement, I have constructed a special kind of formulas that look like algebra but that do not have the same purpose and that to not derive from the same principles: the time when chemistry will have the precision of mathematics is still distant, and I invite you to consider that these formulas are notations whose object is to ease the operations of the mind. (personal translation)

The same principle applies to this new formalism for complex disperse systems (CDS formalism).

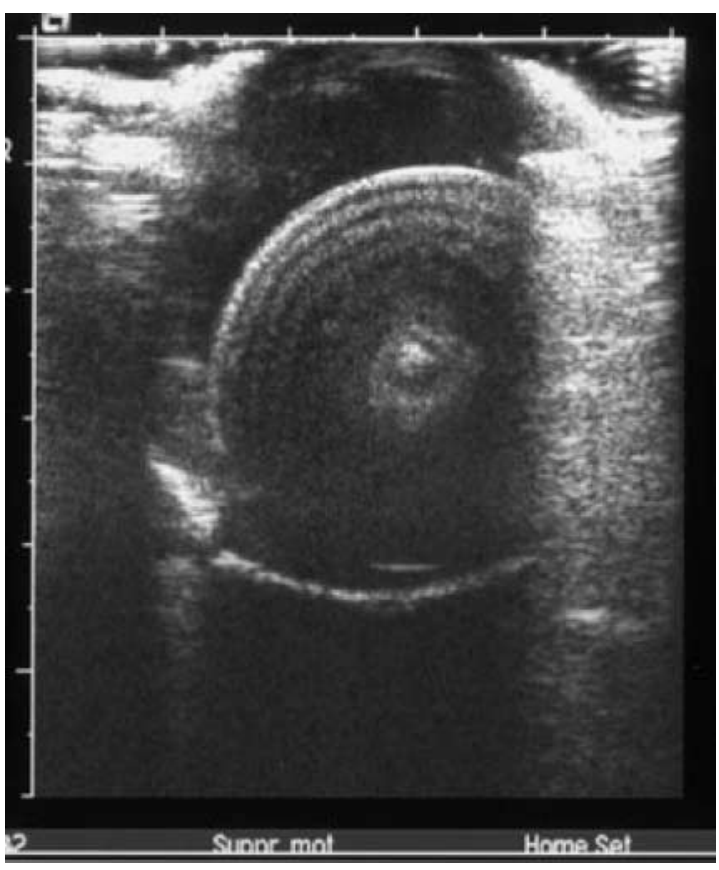

Fig. 1. Echography of an egg yolk (picture Bruno This). 
The following example will illustrate how complex dishes can be described physically using the CDS formalism.

Puff pastry is obtained by including a layer of butter (B) in an envelope made of dough (D), that is stretched and folded into three; the process of stretching and folding is repeated six times

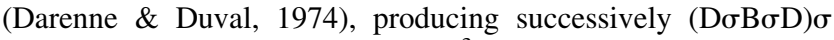
$(\mathrm{D} \sigma \mathrm{B} \sigma \mathrm{D}) \sigma(\mathrm{D} \sigma \mathrm{B} \sigma \mathrm{D})$, or $\mathrm{D} \sigma(\mathrm{B} \sigma \mathrm{D})^{\sigma 3}$ (two layers of dough $\mathrm{D}$ that come in contact make one), then $\mathrm{D} \sigma(\mathrm{B} \sigma \mathrm{D})^{\sigma 9}, \mathrm{D} \sigma(\mathrm{B} \sigma \mathrm{D})^{\sigma 27}$, $\mathrm{D} \sigma(\mathrm{B} \sigma \mathrm{D})^{\sigma 81}, \operatorname{D} \sigma(\mathrm{B} \sigma \mathrm{D})^{\sigma 243}$, and finally $\mathrm{D} \sigma(\mathrm{B} \sigma \mathrm{D})^{\sigma 729}$. As dough is a dispersion of starch granules $\left(S_{1}\right)$ in a gluten network $\left(S_{2}\right)$, and butter has the formula (W/O)/S (Lopez et al. 2002), the final formula of puff pastry is (neglecting the proportions of the ingredients): $\left(\mathrm{S}_{1} / \mathrm{S}_{2}\right) \sigma((\mathrm{W} / \mathrm{O}) / \mathrm{S}) \sigma\left(\mathrm{S}_{1} / \mathrm{S}_{2}\right)^{\sigma 729}$.

CDS formalism was recently applied to the hundreds of classical sauces given by the French official textbook of cooking (Gringoire \& Saulnier, 1901). These sauces were studied using optical microscopy, and the complete formulas were found. In many cases, the formula could be simplified. This modelling led to the discovery that all the French classical sauces belong to 23 groups only: $\mathrm{W}, \mathrm{O}, \mathrm{W} / \mathrm{S}, \mathrm{O} / \mathrm{W}, \mathrm{S} / \mathrm{W},(\mathrm{O}+\mathrm{S}) / \mathrm{W},(\mathrm{W} / \mathrm{S}) / \mathrm{W}, \mathrm{O}+(\mathrm{W} / \mathrm{S})$, $(\mathrm{G}+\mathrm{O}) / \mathrm{W}, \quad(\mathrm{G}+\mathrm{O}+\mathrm{S}) / \mathrm{W}, \quad(\mathrm{O}+(\mathrm{W} / \mathrm{S})) / \mathrm{W}, \quad(\mathrm{S}+(\mathrm{W} / \mathrm{S})) / \mathrm{W}$, $((\mathrm{W}+\mathrm{S}) / \mathrm{O}) / \mathrm{S},(\mathrm{O}+\mathrm{S}+(\mathrm{W} / \mathrm{S})) / \mathrm{W},((\mathrm{W} / \mathrm{S})+(\mathrm{W} \supset \mathrm{S})) / \mathrm{W},(\mathrm{O}$ $+(\mathrm{W} / \mathrm{S}) / \mathrm{W}) / \mathrm{S}, \quad((\mathrm{O}+(\mathrm{W} / \mathrm{S})) / \mathrm{W}) / \mathrm{S}, \quad(\mathrm{O} / \mathrm{W})+((\mathrm{G}+\mathrm{O}) / \mathrm{W})$, $(\mathrm{O}+(\mathrm{W} / \mathrm{S})+(\mathrm{W} \supset \mathrm{S})) / \mathrm{W}, \quad(\mathrm{S}+(\mathrm{W} / \mathrm{S})+(\mathrm{W} \supset \mathrm{S})) / \mathrm{W}, \quad(((\mathrm{W} / \mathrm{S})$ $+(\mathrm{W} \supset \mathrm{S})) / \mathrm{W}) / \mathrm{S}, \quad(\mathrm{O}+\mathrm{S}+(\mathrm{W} / \mathrm{S})+(\mathrm{W} \supset \mathrm{S})) / \mathrm{W}, \quad(\mathrm{O}+\mathrm{S}+((\mathrm{G}$ $+\mathrm{O}) / \mathrm{W})) / \mathrm{W}$.

It is strange that this list does not include such systems as simple as $(\mathrm{G}+(\mathrm{W} / \mathrm{S})) / \mathrm{W}$, that could be made, for example, by mixing whipped egg white in a 'velouté', i.e. a sauce obtained by cooking a roux (butter and flour heated until the mixture turns slightly brown) with an aqueous solution (stock, milk, etc.) (Académie des gastronomes \& Académie culinaire de France, 1991).

\section{What does cooking mean?}

Describing ingredients and dishes is only one part of the modelling process, the other part being culinary transformations. What does 'cooking' mean, in particular?

The same word is used for many different processes, as heat treatment generates very different modifications in vegetables and meats, even if the physical structure of the plant and animal tissues is similar, with water (and many other compounds) dispersed into solids, in cell structures (W/S). Moreover, cooking is generally considered as the application of a thermal treatment, but there are many other possibilities. For example, 'fish cooked à la tahitienne' (ceviche, in Spanish-speaking countries) are obtained through maceration of fish in lime juice. Is the fish really 'cooked'? In order to answer this question, let us consider egg white, primarily made of water and proteins. The most important proteins of egg white are globular, with hydrophobic parts buried at the centre of the molecules (Cotterill, 1973; Vadehra \& Nath, 1973; Creighton, 1983).

In 1996, we demonstrated that the strongest chemical forces established during cooking egg whites are disulfide bridges: adding some reducing compound, such as sodium borohydride $\left(\mathrm{NaBH}_{4}\right)$, to cooked egg white can 'uncook' it by reducing the disulfide bridges (This, 1996a,b). How much should the protein 'uncoil' during cooking? The question can be studied by adding some ethanol to an egg white: immediately it coagulates. Is it 'cooked'?

'Egg white poached with ethanol' can be compared to what we called 'minus century eggs' (This, 1999), obtained by putting eggs in vinegar: the shell is dissolved by acetic acid in some hours, then water goes into the egg by osmosis, and, after about one month, the egg becomes comparable to hard boiled egg. Is it cooked? As no heat treatment is applied, we proposed to introduce a new word 'coction' based on the same Indo-European root 'kok' as 'cooking'. The proposal was done through email to 6357 people (email distribution list of the monthly INRA Seminars of Molecular Gastronomy) and $90 \%$ of people who answered agreed that this new word should now be used for 'cooking without thermal treatment'. A letter giving the results of the vote was sent recently to the Secrétaire perpétuel of the Académie française.

Of course, transforming food (animal or plant tissues) can be done in many ways, and a lot of new techniques can be introduced in the kitchen. But it should not be forgotten that the way we eat is primarily due to culture, which explains why culinary innovation is so slow. Microwave ovens were not easily introduced in kitchens, and 'high-pressure cooking', based on a technique invented for sterilization in the $1910 \mathrm{~s}$ by microbiologists, is today used only by the food industry. Food neophobia (the 'fear of the new', common to all animals) is probably responsible for part of the limited application of such techniques (Simmen \& Hladik, 1998), but we should not overlook the fact that craft is only a minor part of what cooks do: art is over craft, and 'love' (either the love that the cook gives to the consumers, or the love of people sharing a meal) is probably over art, and craft.

\section{Precisions by tens of thousands}

The second main aim of molecular gastronomy is the test of what are now called 'precisions'. Since the 1980s, a lot of precisions have been tested, and the number of precisions now collected from French culinary books is more than 20000 .

Is it true that pears stay white when lemon juice is added, in a pear jam? The answer is yes, and it is well understood that ascorbic acid inhibits polyphenoloxidase enzymes. When pears and other fruits are cut, these enzymes transform liberated polyphenols such as chlorogenic acid and (-)-epicatechin into reactive quinones, which can in turn (Goupy et al. 1995; Grotte et al. 2000) polymerize into darkened pigments. It is easily observed that the browning process is inhibited by lemon juice.

Is it true that pears turn red when cooked in tin-covered copper pans? During public lectures, we performed numerous tests with common pears (Passe Crassane, Williams, Red Williams, Comice, Conference...) and never observed the expected red colour. Model tests using tin ions did not produce the red colour, but such a colour was obtained when $\mathrm{pH}$ was lower than 2 for many varieties. This is easily attributed (Belitz \& Grosch, 1999) to anthocyanidins from the fruits, that turn red in acidic medium (UV-visible spectroscopy: $\lambda_{\max }=522 \mathrm{~nm}$ ). Coloration is particulary deep near the pear skin, where anthocyanidins must be more concentrated.

Is it true that mayonnaise sauce fails when made by menstruating women? This precision has been tested experimentally, and was proved wrong. Is it true that mayonnaise sauce fails when made during a full moon? Students at Tours University (MST Le goût et son environnement, promotion 2000-2001) tested this old wives' tale... and their first test showed a failure; however, the other ones, done immediately after this first failure, were successes. As only one counter example is enough to refute a precision, it can be said that the old wives' tale is wrong. Is it 
true that mayonnaise sauce succeeds only when eggs and oil are at the same temperature? An experiment was performed with eggs at $4^{\circ} \mathrm{C}$ and oil (sunflower) at $24^{\circ} \mathrm{C}$, or with eggs at $24^{\circ} \mathrm{C}$ and oil at $4^{\circ} \mathrm{C}$, and both sauces were successful (This \& Conticini, 1998). Indeed, there is no reason why the sauce could fail in all the circumstances described by old wives' tales, as it is only an emulsion, i.e. a dispersion of oil droplets in the water of the yolk and vinegar, with proteins and phospholipids from the egg stabilizing (it would be more appropriate to write 'metastabilizing', as emulsions are not thermodynamically stable) the droplets.

All possibilities arise: some precisions seem wrong and they are wrong (1); some seem wrong and they are true (2); some seem true and they are wrong (3); and some seem true and they are true (4). We shall now give shortly an example of each, adding a fifth class, of uncertain precisions (5).

(1) As we have demonstrated, it does not seem true, and indeed is not true that menstruation prevents women preparing mayonnaise, as it is proposed in France (This, 1995a,b). Indeed, it is strange that this old wives' tale is told in France yet not in England or in other countries. It demonstrates how much cooking is rooted in culture, and also that culinary activities of today are the fruit of empiricism. In particular, it is an indication of the fact that recipes that can easily fail induce more precisions than others.

(2) In 1994, it was examined whether the skin of suckling pigs has more crackling when the head of the pig is cut immediately after being roasted (This, 1994). This advice seems wrong, but it proved to be true. Alexandre-Balthazar Grimod La Reynière wrote in L'Almanach des gourmands that 'suckling pigs should have the head cut immediately when the pigs are taken out from the oven, otherwise their skin softens'. The same advice lies in many other culinary books. For example, Marie Antoine Carême (1847) indicates to make a cut around the neck ('When you are ready to serve, you separate immediately, with the tip of the knife, the skin of the neck, so that the skin says crisp, which make most of the interest of roasted suckling pigs').

These remarks are strange, as in roasted pigs, no fluid seems to exchange between the head and the skin; it was highly unlikely that the advice was true, but the experiment was performed (public experiment at Saint-Rémy-l'Honoré-Yvelines, France, 7 July 1993) with four suckling pigs of the same parents, reared together in the same farm, weight $7.1-7.3 \mathrm{~kg}$, cooked on a large outside fire from 16.00 to 21.00 hours, one head cut for each pair of pigs. Blind tasting for 143 people showed that the skin of pigs with head cut was crispier.

The mechanism behind was easily discovered, as it was observed during cooking that a stream of vapour was escaping one pig from a hole made during the preparation. It means that heat is evaporating water from the surface of the meat during cooking, making the crust, and vapour formed inside the meat is not enough to compensate for the loss of surface water. When the pigs are not heated any longer, the crust softens if vapour goes through; cutting the head prevents vapour perfusion, as it escapes through the opening.

(3) It is said that the pan where green beans are cooked should not be covered, as it would keep volatile acids, that would promote pheophytinization of chlorophyll (Gauthier-Jacques et al. 2001), but tests show that there is no colour difference. The idea seems true, but it is wrong.

(4) It is sometimes said that the soufflés should be made from very firm whipped egg whites, added to a viscous preparation (Larousse Gastronomique, 1988). It was demonstrated that this precision holds, as vapour bubbles formed in the bottom part of soufflés, during cooking, escape less through firm foam (This, 2002). The advice seemed true, and it is true.

(5) Let us now discuss a fifth class, with precisions having a non-clear-cut status. For example, it is sometimes said by cooks that vinegar is less acidic when boiled (Blanc et al. 1994). However, with N. Kurti, we showed that various vinegars give various results... as they are not solutions of acetic acid in water, but also contain various concentrations of many other compounds, such as malic acid, lactic acid, etc.

Plant diversity is the reason why some precisions have a nonconstant status, but there are also cases when the environmental conditions of the precisions changed. For example, it has been written that red fruits should never been put in contact with tin (Saint Ange, 1925). When fruits such as raspberries are put in contact with metallic tin, no modification appear, but when $\mathrm{Sn}^{2+}$ ions are deposited on crushed raspberries, a purple, turning to black, colour appears, because the complex of anthocyanins with $\mathrm{Sn}^{2+}$ ions shifts a peak in the absorption spectrum toward shorter wavelengths (This, 1995a,b; Belitz \& Grosch, 1999).

\section{Why do precisions arise?}

Why have all the collected precisions arisen? Considering the way culinary craft has developed, it can be easily assumed that failures and successes generated assumptions concerning the experimental protocol used. For example, in the old recipe of 'mayonnaise' below (Bernardi et al. 1853), the inverse order of ingredients should have frequently led to failure:

Green Rémolade. Take a handful of chervil, tarragon, you will blanch these herbs that are called Ravigote; press and grind, add salt, pepper, mustard: grind all together, then add half a glass of oil that you amalgamate with the ravigote and mustard; finally you add two or three egg yolks.

How strange a process: the authors are describing an emulsion but they add the surfactants (proteins and lecithin from the yolk) at the end (happily, there are some phospholipids and proteins, as well as water, in the ground herbs)! The frequent failure should have led them to investigate the causes of the irregularity of the process, and 'precisions' should have arisen naturally.

This observation leads to a prediction: if it is true that precisions come from failures, then an inverse quantitative relationship should exist between the 'robustness' of a recipe and the number of precisions written in culinary books.

In order to test experimentally this prediction, robustness has first to be made quantitative. Let us consider that a recipe $R$ is a function of many variables: various times $\left(t_{1}, t_{2}, \ldots\right)$, temperatures $\left(T_{1}, T_{2}, \ldots\right)$, ingredients $\left(m_{1}, m_{2}, \ldots\right)$, details of process $\left(p_{1}\right.$, $\left.p_{2}, \ldots\right)$, etc.

For example, in a mayonnaise recipe, the process can be described by the amount of egg yolk (a parameter including water content, protein content, lecithin content, etc.), the amount of vinegar (i.e. water at the first order), the rate of oil addition, the energy of whipping.

A product $\mathrm{P}$ obtained through the recipe using particular conditions is given by the equation:

$$
P=R\left(t_{1}, t_{2}, \ldots, T_{1}, T_{2}, \ldots, p_{1}, p_{2}, \ldots\right) .
$$

Or more generally $P=R\left(x_{i}, y_{j}\right)$, the $x_{i}$ being parameters describing the ingredients, the $y_{j}$ parameters describing the process, $i$ and $j$ being integers from 1 to, respectively, $n$ and $m$. 
As long as the parameters vary within certain limits $\left(x_{i \text {, min }}<\right.$ $x_{i}<x_{i, \text { max }}, y_{j \text {, min }}<y_{j}<y_{j, \max }$ ), the recipe is successful: a product is the result of a successful recipe if it is a point inside a hypervolume in the multidimensional space of the parameters.

For each parameter of the recipe, the interval $x_{i, \max }-x_{i, \min }$ is clearly a measure of the robustness but in order to get a nondimensional value that can be compared to others, we need to divide $x_{i, \max }-x_{i, \min }$ by a number having the same units. We propose to normalize by the uncertainty $i\left(x_{i}\right)$ on the considered variable $x_{i}: \rho_{i}=\Delta x_{i} / i\left(x_{i}\right)$. Of course, orders of magnitudes have to be calculated instead of exact values, as the uncertainty is only known as estimation.

For example, mayonnaise can be defined by the mass of yolk $m(\mathrm{y})$, the mass of vinegar $m(\mathrm{v})$, the mass of oil $m(\mathrm{o})$, the mass of salt $m(\mathrm{~s})$, the mass of pepper $m(\mathrm{p})$, the mass of oil in each successive addition $m(\mathrm{~d})$, the whipping power $P_{\mathrm{w}}$, the efficiency of dispersion $E_{\mathrm{d}}$. As the critical parameter is clearly the oil addition, let us focus on robustness related to oil addition: in the beginning of mayonnaise preparation, oil should not be added too fast, because water-in-oil emulsion is obtained instead of oil-in-water emulsion. As the quantity of water from one yolk and one teaspoon of vinegar is about $20 \mathrm{~g}(=15 \mathrm{~g}+5 \mathrm{~g}$; Belitz \& Grosch, 1999), and by the uncertainty on the oil quantity added each time (estimation based on experiments, $7.5 \mathrm{~g}$ ), robustness related to oil addition is equal to $20 / 7 \cdot 5=2 \cdot 7$.

In more 'robust' recipes, such as beef meat roasted in the oven, the calculated robustness is bigger: for a piece of meat of mass $1 \mathrm{~kg}$, cooked at $180^{\circ} \mathrm{C}$ for a time between 20 and $60 \mathrm{~min}$, robustness is equal to $(60-20) / 5=8$. If the cooking temperature is lower (e.g. $\left.70^{\circ} \mathrm{C}\right)$, then the cooking time interval would be still bigger, and robustness higher: the time interval could be estimated to be between $60 \mathrm{~min}$ and 1 day, so that the robustness is equal to $1440 / 5=276$.

For some recipes, parameters are not independent, and success is obtained only if more than one condition is simultaneously verified. Particular robustnesses have to be aggregated. In order to do it, let us assume that robustness is inversely related to the number of precisions: $\rho=1 / n$. If the total number of precisions is the sum of number of precisions $n_{1}, n_{2}, \ldots$ for classes $i$ of precisions, then for each class: $\rho_{i}=1 / n_{i}$. Hence

$$
\rho=1 /\left(n_{1}+n_{2}+n_{3}+\cdots\right)=1 /\left(1 / \rho_{1}+1 / \rho_{2}+\cdots\right),
$$

or

$$
1 / \rho=1 / \rho_{1}+1 / \rho_{2}+\cdots
$$

Does the inverse relation hold? In the precisions that we have collected since 1980, there are 105 paragraphs about mayonnaise preparation, compared to twelve paragraphs for roasts.

In Fig. 2, we show how robustness $\rho$ depends on the number of paragraphs containing precisions for grated carrots, stock, soufflé, boiled eggs, gougères, mayonnaise, beef roast. In the figure stock is included, and the curve does not correspond to an inverse relation: stock generated many precisions only because of its culinary importance, even if there is almost no risk of failure. If the last point at the right, corresponding to stock, is excluded, the relationship is more as expected.

More work needs to be done to test our assumption, using the aggregation relation of partial robustnesses $\left(1 / \rho=1 / \rho_{1}+1 / \rho_{2}+\ldots\right)$, but also to look for the signification of derivation of the equation defining products; what does a high partial derivative $\delta R / \delta_{x_{i}}$ mean?

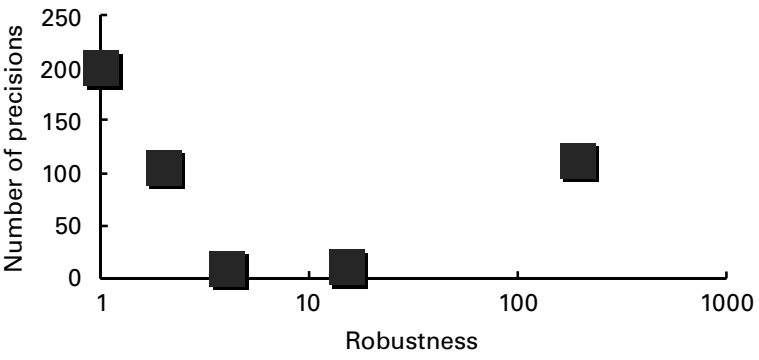

Fig. 2. The relationship between robustness $\rho$ of recipes $v$. number $n$ of paragraphs mentioning each recipe. Without stocks (right most point), the law is almost $\rho=1 / n$ (the exponent is exactly $1 \cdot 12$ ).

\section{From science to technology}

Science is only interested in knowledge, but technology is applying new knowledge to craft. Here, we shall now see how molecular gastronomy can be applied in the kitchen.

Let us apply first the formula of complex dispersed systems to traditional processes. For example, production of whipped cream could be described by:

$$
\mathrm{O} / \mathrm{W}+\mathrm{G} \rightarrow(\mathrm{G}+\mathrm{O}) / \mathrm{W}
$$

Indeed cream can be considered as an oil-in-water emulsion $(\mathrm{O} / \mathrm{W})$; whipping is used to introduce air bubbles.

This process can be generalized: in 1995, we introduced a new dish named 'Chocolate Chantilly', based on Eq. (1) (This, 1996a,b). First make a chocolate emulsion $\mathrm{O} / \mathrm{W}$ by melting some chocolate into water (the proportion of chocolate and water has to be chosen so that the final fat/water ratio is about the same as the ratio in ordinary cream). Then put the pan on ice (to cool it faster) and whip $(+\mathrm{G})$ : after some time (some minutes, depending of the efficiency of the cooling), a 'chocolate mousse' $(\mathrm{G}+\mathrm{O}) / \mathrm{W}$ is obtained.

What is interesting, in this case, is that this mousse does not contain eggs, and that the texture can be the same as in whipped cream. This system is named 'Chantilly cream' when sugar is present; hence the name 'chocolate Chantilly' given to the new dish (see Fig. 3). Of course, the same equation can be used with other fat, chocolate being replaced by cheese or foie gras, or even butter, leading to cheese 'Chantilly' or 'foie gras Chantilly', or 'butter Chantilly' (This \& Gagnaire, 2003).

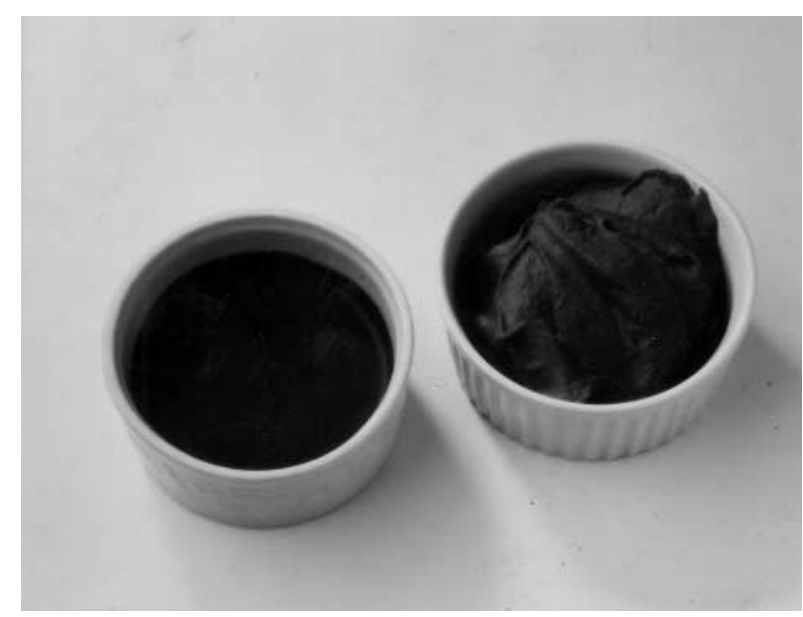

Fig. 3. A 'chocolate emulsion' (left) and a 'Chocolate Chantilly' (right). 
(A)

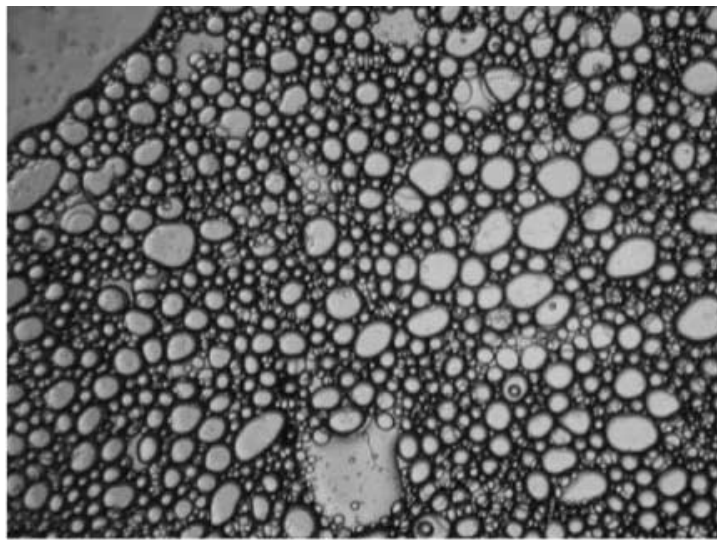

(B)

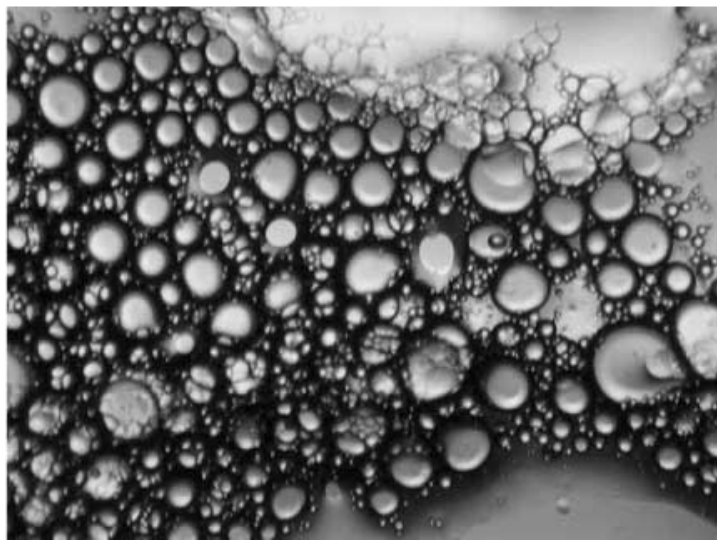

Fig. 4. Oil-in-water emulsion (A) made from water, gelatin and oil; when it cools, a 'jellified physical emulsion' forms (B).

Another example shows that the use of these formulas led to new systems with both scientific and culinary interest. The formula O/W can be made with oil dispersed into water using surfactants. For example, if oil is whipped into an egg white, the egg proteins can make a 'mayonnaise without egg yolk', which is an emulsion oil-in-water $(\mathrm{O} / \mathrm{W})$. If, instead of egg white, oil (about $200 \mathrm{ml}$ ) is added to a solution of gelatin $(5 \mathrm{ml}$ water plus $0.5 \mathrm{~g}$ of gelatin), an $\mathrm{O} / \mathrm{W}$ system is also obtained. In this second case, there is some slow coalescence until the gel is set. Finally, a jellified emulsion is made: $\mathrm{O} / \mathrm{W}+\mathrm{S} \rightarrow(\mathrm{O} / \mathrm{W}) / \mathrm{S}$ (see Fig. 4).

The jellified emulsion that is made from water, gelatin and oil is a physical gel, i.e. a reversible system. Would it be possible to make a chemical gel trapping an emulsion? If an emulsion made from egg white and oil is heated (1 min, kitchen microwave oven, full power) so that some swelling of the emulsion is obtained, the temperature $\left(100^{\circ} \mathrm{C}\right)$ is above $61^{\circ} \mathrm{C}$ where egg coagulation occurs, and a chemically jellified emulsion is obtained (see Fig. 5).

\section{A wealth of new dishes}

A generalization is obvious. Let us consider any formula, with letters $\mathrm{A}, \mathrm{B}, \mathrm{C}, \ldots, \mathrm{K}$ and symbols chosen as described. For example:

$$
\left.\left(\left(\mathrm{G}+\mathrm{S}_{1}+\mathrm{O}\right) / \mathrm{W}\right) / \mathrm{S}_{2}\right)
$$

Such a formula can lead to a new dish. For example, with the formula above, a gas $(\mathrm{G})$, two solids $\mathrm{S}_{1}$ and $\mathrm{S}_{2}$, one oil $\mathrm{O}$ and one water phase $\mathrm{W}$ are to be made.

Let us assume that the dish should have the taste of lobster. The cook could:

(1) Prepare a lobster flavoured oil, by heating lobster shells in oil: O.

(2) Prepare a lobster purée by grinding lobster meat: $S_{1}$.

(3) Prepare a lobster soup by cooking shells with onions, carrots, thyme, laurel, tomatoes, etc.: $\mathrm{W}$.

(4) Disperse the puree $S_{1}$ and the oil $O$ into the soup W with gelatine as a surfactant:

$$
\left.\mathrm{S}_{1}+\mathrm{O} \rightarrow\left(\mathrm{S}_{1}+\mathrm{O}\right) / \mathrm{W}\right)
$$

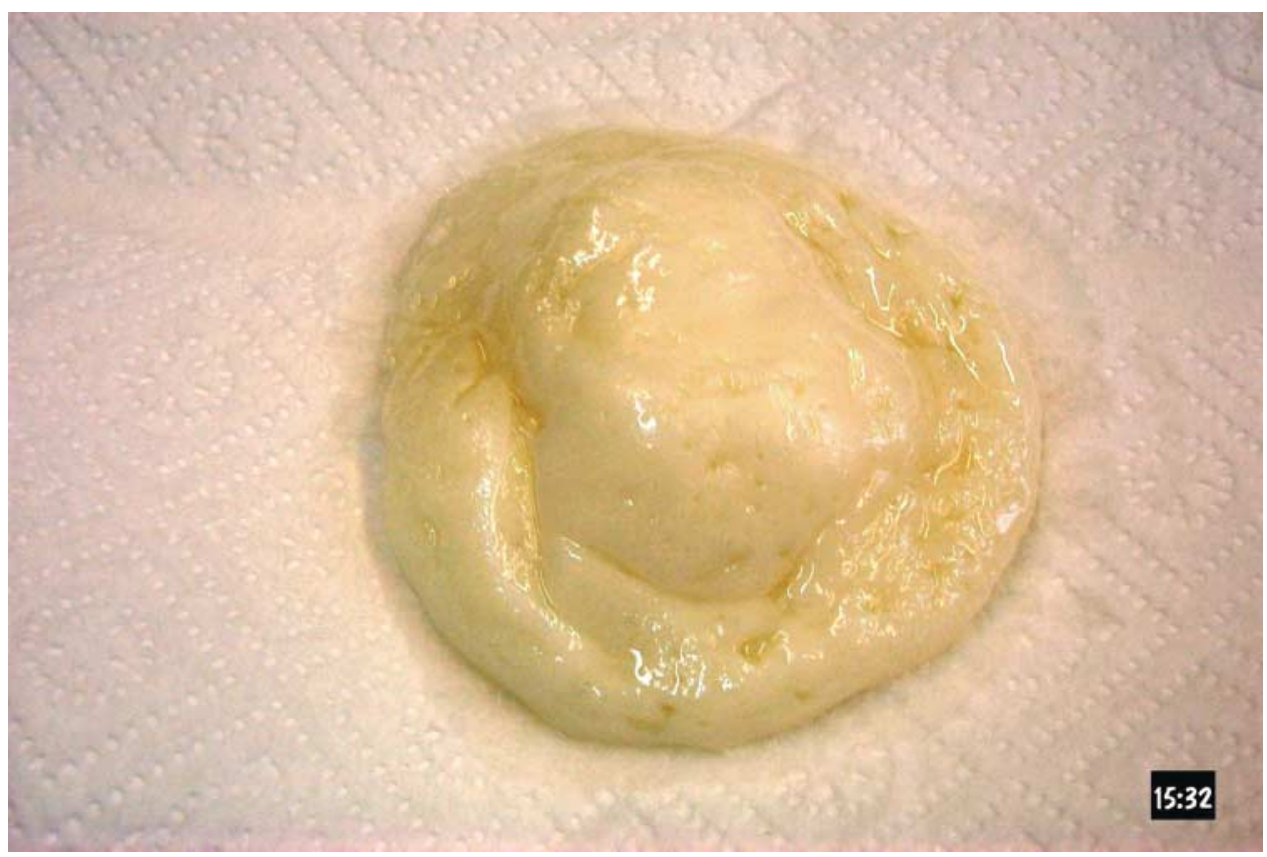

Fig 5. A chemical gel trapping an oil-in-water emulsion. 
(5) Introduce some air into the emulsion:

$$
\left(\left(\mathrm{S}_{1}+\mathrm{O}\right) / \mathrm{W}\right)+\mathrm{G} \rightarrow\left(\mathrm{S}_{1}+\mathrm{O}+\mathrm{G}\right) / \mathrm{W} .
$$

(6) Wait until the gelatin makes the gel:

$$
\left(\mathrm{S}_{1}+\mathrm{O}+\mathrm{G}\right) / \mathrm{W}+\mathrm{S}_{2} \rightarrow\left(\left(\mathrm{S}_{1}+\mathrm{O}+\mathrm{G}\right) / \mathrm{W}\right) / \mathrm{S}_{2} .
$$

A name should be given to this dish: 'Faraday of lobster' was chosen of this dish when it was first served by the French cook Pierre Gagnaire (Restaurant Pierre Gagnaire, Paris). Of course, the same formula applies to many dishes: with a carrot taste instead of lobster, or any possibility. The number of possibilities is innumerable, but not all the formulas are either possible or interesting, and some formulas can be simplified. For example, $\mathrm{O} / \mathrm{O}=\mathrm{O}$ (and more generally $\mathrm{X} /$ $\mathrm{X}=\mathrm{X}$ ). Furthermore, $\mathrm{X} / \mathrm{G}$ systems are not interesting, from the eating point of view.

\section{Back to scientific strategy}

How will it be possible to investigate precisions, if more than 20000 of them have to be tested, as one test (including research on the mechanisms behind the effect have to be examined) needs often weeks of studies?

The strategy is now to create 'Molecular Gastronomy Workshops' in culinary schools, and to introduce some research activities in the curriculum. If 500 culinary schools were testing only four precisions per year, 10 years would be enough to produce 'clean' culinary books for the next generation of cooks. This would be helpful, because the tests themselves do not generally need a high level in science, and molecular gastronomy could focus on modelling definitions.

Molecular gastronomy workshops have been active for some years, and their number is growing worldwide, as well as seminars in molecular gastronomy, and other molecular gastronomy activities. In France, the culinary curriculum has been modified through molecular gastronomy, and in other countries also molecular gastronomy can be used to improve culinary education at various levels, from basic school to university. But we are still far from the point where all citizens, in all countries, cook using sound, scientific and rational ideas.

\section{References}

Académie des gastronomes, Académie culinaire de France (1991) L'art des sauces. Paris: J. T. Lanore.

Anonymous (1905) Anonymous le livre de cuisine de Tante Colette. Paris: François Tedesco.

Atkins PW (1998) Physical Chemistry. New York: Freeman and Co.

Belitz HD \& Grosch W (1999) Food Chemistry, Heidelberg: Springer Verlag.

Bernardi M, Viart M, Fouret M \& Délan M (1853) Le cuisinier national de la ville et de la campagne (ex Cuisinier royal), augmenté de 200 articles nouveaux, p. 49. Paris: Gustave Barbu.

Blanc R, Kurti N \& This H (1994) Blanc Mange. London: BBC Books.

Bloch O \& Von Wartburg W (1975) Dictionnaire étymologique de la langue française, p. 221. Paris: Presses universitaires de France.

Carême MA (1847) L'Art de la Grande Cuisine française, t. 3, p. 481. Paris: Kerangue et Pollies.

Cotterill OJ (1973) In Egg Science and Technology [WJ Stadelman and OJ Cotterill, editors]. Westport, CT: AVI Publishing.
Creighton TE (1983) Proteins. New York: WC Freeman and Co.

Darenne E \& Duval E (1974) Traité de pâtisserie moderne, pp. 58-60. Paris: Flammarion.

De Gennes PG (1997) Soft interfaces. In The 1994 Dirac Memorial Lecture. Cambridge: Cambridge University Press.

De Gennes PG (1999) La matière molle. In La juste argile [M Daoud and C Williams, editors]. Paris: EDP Sciences.

De Gennes PG, Brochard-Wyart F \& Quéré D (2002) Gouttes, bulles, perles et ondes, pp. 0. Paris: Belin.

Dickinson E (1994) Emulsions stability. In Food Hydrocolloids, Structure, Properties and Functions [K Nishinari and E Doi, editors]. New York: Plenum Press.

Djabourov M (1988) Architecture of gelatine gels. Contemp Phys 29, 273-297.

Everett DH (1988) Basic Principles in Colloid Science. London: Royal Society of Chemistry.

Galileo Galilei (1623) L'essayeur. In Galilée ou l'avenir de la science, pp. 133-134 [W Fritsch, editor]. Paris: Seghers.

Gauthier-Jacques A, Bortlik K, Han H, et al. (2001) Improved method to track chlorophyll degradation. J Agric Food Chem 49 , $1117-1122$.

Gouffé J (1867, new edition 1988) Le livre de cuisine. Paris: Henri Veyrier.

Goupy P, Amiot MJ, Aubert S, et al. (1995) Apple phenolic compounds and enzymatic oxidation in model solutions by apple polyphenoloxidases. In Polyphenols 94, pp. 183-184 Paris: Inra editions.

Gringoire L \& Saulnier T (1901) Répertoire général de cuisine. Paris: Flammarion.

Grotte M, Duprat F, Loonis D, et al. (2000) Aspects des meutrissures des pommes. Science des aliments 20, 575-590.

Hiemnez PC (1986) Principles of Colloid and Surface Chemistry. New York: Marcel Dekker Inc.

Hunter RJ (1986) Foundations of Colloid Science. Oxford: Oxford University Press.

Largeault J (1988) Principes classiques d'interprétation de la nature, p. 28. Paris: Librairie philosophique Vrin/Institut interdisciplinaire d'études épistémologiques.

Larousse Gastronomique (1988) Paris: Larousse.

Lavoisier AL (1782) Considérations générales sur la dissolution des métaux dans les acides, Mémoires de l'Académie des sciences. In Oeuvres complètes, t. II, pp. 509-527.

Lehn JM (1995) La chimie supramoléculaire. Weinheim: VCH.

Lopez C, Bourgaux C, Lesieur P, et al. (2002) Crystalline structures formed in cream and anhydrous milk fat at $4^{\circ} \mathrm{C}$. In Lait 82 , pp. $317-335$.

Lyklema J (1991) Fundamentals of Interface and Colloid Science. London: Academic Press.

Poincaré H (1900) La valeur de la science. Paris: Flammarion.

Saint Ange M (1925) Rappelons que, pour la manipulation des fruits rouges, l'emploi de tout ustensile étamé doit être écarté. In La bonne cuisine de Madame Saint Ange, p. 954. Paris: Larousse.

Simmen B \& Hladik CM (1998) Sweet and bitter taste discrimination in primates: scaling effects across species. Folia Primatol 69, $251-257$.

Sztehlo A (1994) Investigation of the structure of ice cream by light microscopy. Eur Microsc Anal 5, 27-31.

This H (1994) La cuisson: usages, tradition et science. In La cuisson des aliments, pp. $13-21.7^{\mathrm{e}}$ rencontres scientifiques et technologiques des industries alimentaires, Agoral 94.

This H (1995a) La gastronomie moléculaire et physique, $\mathrm{PhD}$ Thesis, University Paris VI.

This H (1995b) La gastronomie moléculaire. L’Actualité chimique 6 42-46.

This H (1996a) Can a cooked egg white be 'uncooked'? The Chemical Intelligencer 10, 88 .

This H (1996b) Le chocolat Chantilly. Pour la Science 230, 20.

This H (1999) L'oeuf de 100 ans. Pour la Science 264, 8. 
This H (2002) Molecular gastronomy. Angew Chem Int Ed Engl 41, 83-88. This H (2003) La gastronomie moléculaire. Science des aliments 23, $187-198$.

This H \& Conticini C (1998) Toques à la loupe. In France 5 (formerly la Cinquième programme).
This H \& Gagnaire P (2003) http://www.pierre-gagnaire.com

This H \& Kurti N (1994) Physics and chemistry in the kitchen. Sci Am 270, 44-50.

Vadehra DV \& Nath KR (1973) Eggs as a source of protein. CRC Crit Rev Food Sci Technol 4, 193-309. 